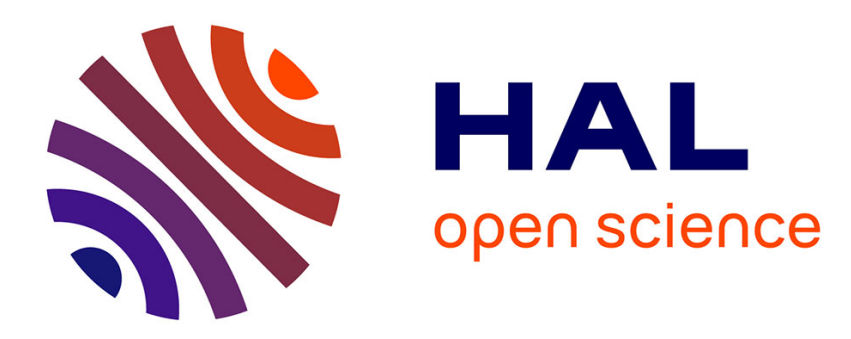

\title{
Genetic Testing, Birth, and the Quest for Health Joëlle Vailly
}

\section{To cite this version:}

Joëlle Vailly. Genetic Testing, Birth, and the Quest for Health. Science, Technology, and Human Values, 2014, 39, pp.374 - 396. 10.1177/0162243913509413 . hal-01081996

\section{HAL Id: hal-01081996 https://hal.science/hal-01081996}

Submitted on 12 Nov 2014

HAL is a multi-disciplinary open access archive for the deposit and dissemination of scientific research documents, whether they are published or not. The documents may come from teaching and research institutions in France or abroad, or from public or private research centers.
L'archive ouverte pluridisciplinaire HAL, est destinée au dépôt et à la diffusion de documents scientifiques de niveau recherche, publiés ou non, émanant des établissements d'enseignement et de recherche français ou étrangers, des laboratoires publics ou privés. 


\title{
Genetic Testing, Birth, and the Quest for Health
}

\author{
Joëlle Vailly* \\ *Inserm, Institut de recherche interdisciplinaire sur les enjeux sociaux (Iris, CNRS, Inserm, \\ EHESS, Université Paris 13), Bobigny, France
}

\begin{abstract}
Newborn screening for genetic diseases has developed rapidly in Western countries. These biopolitics raise the question of birth as a sociological "knot" insofar as it is the threshold between the (possibly ill or disabled) child and the fetus. The question therefore addressed in this text, based on a field study of newborn screening for cystic fibrosis in France, is that of the link between the quest for good health (through treatment) and the elimination of poor health (by prenatal diagnosis). Do they reinforce each other or, on the contrary, are they contradictory? I analyze the positions of both mothers of screened children and clinicians regarding the following three points: prenatal diagnosis to preclude sets of sick siblings, identification of heterozygous individuals and generalized prenatal screening. This study shows how increasingly attentive patient care and an increasingly demanding approach to prenatal diagnosis reinforce one another. It also analyzes the role of taking action early on and evaluating the lives of sick or disabled people in this process. In conclusion, I engage a more general discussion about what I suggest calling a "quality life".
\end{abstract}

Keywords: genetics, newborn screening, biopolitics, life, sociology

This text has been published in: Vailly, J. 2014. Genetic Testing, Birth, and the Quest for Health. Science, Technology, \& Human Values 39(3):374 - 396. 
Newborn screening for genetic conditions has developed rapidly ever since the first publication suggesting a screening test for phenylketonuria, a rare genetic condition, in 1963 (Guthrie and Susi 1963). ${ }^{1,2}$ Fifty years later, roughly 50 conditions are now screened for at birth in the United States, most of which are genetic. ${ }^{3}$ More than four million neonates are screened there every year making newborn screening the most frequent test for genetic conditions in the country (Grob 2011, Timmermans and Buchbinder 2013). In France five diseases are tested for at birth, including cystic fibrosis [mucoviscidose in French] since January 2002 when the country opted to generalize newborn screening for this disease. ${ }^{4}$ This development of newborn screening can be linked to the fact that during the $20^{\text {th }}$ Century the child became the target par excellence for screening as a medical approach (Armstrong 2012). Monitoring and caring for newborns reflects a longer-standing concern with the initial years of life and with perinatal health for, as Michel Foucault explains (2001), the family-child complex was the first focus of medical jurisdiction and infants have long been a preferred target of health policies. These newborn screening programmes are a form of biopolitics which refer us to the emergence, since the $18^{\text {th }}$ Century, of a process through which life, health and welfare have entered into political strategies, allowing the population's state of health to be observed, measured and improved (Foucault 2001). They present the specificity of being carried out at a moment - birth - that seems to constitute a sociological "knot", to paraphrase Ian Hacking (2005), who uses the term to designate a situation resulting from contradictory tendencies. ${ }^{5}$ An initial approach to this question reveals two elements that can be seen as contributing to these tendencies.

First, as Giorgio Agamben $(1998,131)$ writes, "one of the essential characteristics of modern biopolitics (which will continue to increase in our century) is its constant need to redefine the threshold in life that distinguishes and separates what is inside from what is outside". Birth 
certainly strikes people as a threshold separating the (possibly ill or disabled) child from the fetus. Although this seems obvious today, the anthropology of law shows that this threshold has changed (Cayla and Thomas 2002). Historically, the Declaration of Human Rights of 1789 held that the mere fact of being born carried with it certain rights stating that men are born and remain free and equal in rights. As Agamben $(1998,127)$ put it: "Declarations of rights represent the originary figure of the inscription of natural life in the juridico-political order of the nation-state. The same bare life that in the ancien régime was politically neutral and belonged to God as creaturely life [...] now fully enters into the structure of the state and even becomes the earthly foundation of the state's legitimacy and sovereignty." In sum, before 1789, life belonged to God and the King of divine right. After 1789, birth, life and rights have coincided, and this strengthens the threshold effect of birth in terms of rights.

Second, birth represents a turning point between, on the one hand, the fetus and the prenatal diagnosis that can be offered in the case of genetic conditions and, on the other, the lives of people who can be ill or disabled, and the treatment provided to them. Birth makes it possible to bring together two types of practice and two social science research traditions. The first concerns reproductive health or what is at stake in genetic techniques; the second concerns the experience of illness and policies for disabled people, with variants in the latter regarding treatment for the sick and the social integration of disabled people as such. A small number of studies have attempted to combine these questions, through the "disability rights" critique of prenatal diagnosis and possible responses to that critique (Parens and Asch 2000). Others have focused on the tension between the biomedical potential to both screen out imperfect lives and to enable people with significant disabilities to survive and flourish (Rapp and Ginsburg 2001; 2003). Still others have focused on the later reproductive choices of parents with a disabled child (Kelly 2009); the comparative social history of areas in which perinatal 
medicine intervenes and social policies around disability (Ville 2011); or the question of whether newborn screening for and prenatal diagnosis of metabolic diseases are converging or diverging (Buchbinder and Timmermans 2011). The idea informing many of these texts is that there are contradictory viewpoints, or a "knot", between including disabled people in society and excluding disease-affected fetuses. However, most of these authors do not seem to wish to directly address the question of the link between these two approaches on either side of birth; in any case they have not developed methodological means for dealing with this issue as they have not conducted any fieldwork that focuses both on care in the space of pediatrics and on prenatal diagnosis in the space of genetics.

The question therefore addressed in this text, based on my field study of newborn screening for cystic fibrosis (NSCF) in France, is that of the link between the quest for good health (through treatment) and the elimination of poor health (by prenatal diagnosis and the potentially related pregnancy termination). Is there a causal relationship between the two approaches - in other words does one lead to the other - or, on the contrary, are they contradictory? What channels this link and upon what is it grounded? My idea is that analyzing this link on the basis of newborn screening practices will allow an understanding of the sociological significance of certain contemporary biomedical developments.

In the first two sections of this article, I present the points of view of mothers (or parents) whose children were screened at birth, and I then go on to outline the clinicians' points of view in the third section. More specifically, I first describe two ways in which NSCF seems to have extended the likelihood of prenatal diagnosis: prenatal diagnosis to preclude sets of sick siblings and the identification of heterozygous individuals — and the mothers' positive view of this. I then explain how NSCF is changing views on generalized prenatal screening extended to the whole population, through the idea of taking action early on: above all the views of 
mothers (or parents) of children screened positive for the disease, who openly evaluate their child's life and, to a lesser extent, the views of the parents of children who screen negative. Finally, I analyze the clinicians' positions on the following three points in relation to their ethical framework: prenatal diagnosis to preclude sets of sick siblings, identification of heterozygous individuals and generalized prenatal screening. In sum, these different results show how the quest for good health and the matter of eliminating poor health are linked and reinforce one another. In conclusion, I engage a more general discussion about the stakes of these results and in particular what I suggest calling a "quality life".

\section{Presentation of the study}

This research is part of a study of the scientific, political and moral issues involved in NSCF (Vailly 2013). A professional association called the Association Française pour le Dépistage et la Prévention des Handicaps de l'Enfant (AFDPHE; French association for screening and preventing disabilities in children) is responsible for all newborn screening practiced in France. Most of its members are pediatricians and, to a lesser degree, geneticists. Children who screen positive are cared for and followed up in specialized treatment centers called Centres de Ressource et de Compétence de la Mucoviscidose (CRCMs), most of them located in hospitals and staffed by pediatricians, geneticists, physical therapists, etc. My research is based on a seven-month field study conducted in 2005 in a CRCM at a major hospital in the greater Paris metropolitan area. In order to answer the question asked above, I simultaneously studied the "spaces" of pediatrics and genetics. When it is established that a screened child is a carrier of one or two genetic mutations, the parents are encouraged by the pediatrician to attend an appointment with the geneticist. 
The study is based firstly upon observations of pediatric and genetic consultations for cystic fibrosis (128 observations, of which 91 in pediatrics and 37 in genetics). In the center where the study was carried out, the consultations for cystic fibrosis in connection with NSCF are not separated from those in connection with diagnosis from symptoms before screening was implemented. For this reason, approximately one third of the consultations observed were directly linked to NSCF while two thirds were linked to symptom-based diagnoses.

The study is also based on interviews with the mothers of the young children screened at birth and with the clinicians (pediatricians and geneticists) of the CRCM (22 interviews). I interviewed the mothers of screened children whose consultations I observed (12 interviews). ${ }^{6}$ These interviews consisted in retracing in detail each stage of the newborn screening and related follow-up in the case of illness. They also enabled me to obtain the mothers' overall assessment of screening and certain sensitive aspects linked to evaluating the patients' lives.

Comments by fathers directly involved in the medical follow-up of their child and expressing a desire to be present at the interview were included in the research study. The children with cystic fibrosis whose parents I interviewed were all under two years of age. Given that newborns in France are systematically screened for cystic fibrosis, that all children who have tested positive are sent to specialized centers, and that France's universal health insurance pays for almost all treatment, the families I studied represent a wide range of socio-economic situations.

All clinicians of the center (pediatricians and geneticists) were interviewed, including those whose consultations I observed (10 interviews). These interviews focused more specifically on their practices, with the emphasis on how these had changed due to NSCF, on their assessment of this screening and on the patients they were treating. 
A methodological point that should be underlined is that the respondents' questions surrounding the absence of generalized prenatal screening, which I will look at later, always came up spontaneously, with no prior allusions on my part. In order to fully understand these, it is important to know that in France pregnancies may be terminated for medical reasons up to term; there is no legal time limit.

The analysis forming the basis for this article was performed as follows: I noted and classified the various occurrences of what was said about the link between newborn screening and prenatal tests (or screening) and about related points, such as the evaluation of life. A common method for qualitative surveys was applied that consists in adjusting the analysis while investigations go forward. In this way, theoretical notions can be reformulated and hypotheses are generated (Glaser and Strauss 1967).

Finally, this research also calls upon the study of various documents linked to the study (information leaflets on newborn screening, national statistics, etc.).

\section{When newborn screening extends the likelihood of prenatal diagnosis}

The first point of intersection between the quest for good health and the elimination of poor health around birth in fact entails a shift from one to the other. In this section I shall look at how this shift materialized in acts, the channels through which it operates and the foundations upon which it is based.

First, it is necessary to underline that the "quality of life" question is mentioned in most of the written material promoting NSCF. An information sheet on newborn screening distributed to parents in maternity hospitals and clinics specifies that "early, rigorous treatment and followup [...] ensure a higher quality of life for the patient" (AFDPHE 2001). Moreover, the expression "quality of life" was notably used in the press release given to the media when the 
AFDPHE announced the launch of NSCF. It stated: "It is important to screen [for cystic fibrosis] as early as possible, in order to improve the quality of life of screened children and increase their life expectancy" (Assurance Maladie - Sécurité Sociale 2000). This means that as far as physicians are concerned, treating patients early and appropriately is a means of ensuring they will have the best health possible.

But despite treatment efforts, young patients' problems often become more complicated with time. The number of treatment programs and hospitalizations rises as lung infections become chronic. Worse yet, everyone involved - patient, parents, doctors-are in close contact with the tragic dimension of medicine, the fact that we are all mortal (Fox 2000). However the picture is not always so grim. Some adolescents (relatively few in number) do well, and it is hard to imagine they are sick. Given this complex overall picture, the question arises of evaluating a life in which medical treatment looms so large. And the first question is how to proceed during possible future pregnancies.

Before NSCF was set up, when a couple had two children in quick succession the second child might also have the disease whereas the first had not yet been diagnosed with it. Today, newborn screening allows for early diagnosis of the first child, making prenatal diagnosis available for any second pregnancy to ensure that the potential sibling will not have the disease too. Parents of a child who has screened positive and who wish to have another child are encouraged by the CRCM pediatrician to consult a geneticist for a prenatal diagnosis, as attested by the following interview excerpt:

"I told [name of the pediatrician] that I was pregnant and she got an appointment for me right away with the geneticist" (Mother 1).

During my hospital field study, the three mothers whose first child had screened positive for cystic fibrosis requested prenatal diagnosis during their second pregnancy (in all cases the fetus tested negative for the disease). With their experience of the illness, which I will come 
back to later, none of them envisaged giving birth to another sick child. Two of them notably said in interviews:

"I wouldn’t put him through that" [I wouldn’t put my child through that illness]" (Mother 1).

"Anyway, I think I would have made it go away [je l'aurais fait partir in French] because I'd had too many problems [with the first child]" (Mother 2).

Given these results, two initial remarks should be made. The first derives from the fact that some studies, though few in number, show wide differences in parents' point of view after the birth of a sick or a disabled child. Certain studies have found that parents are likely to feel that carrying out a prenatal diagnosis on the fetus of a possible second child would indicate rejection of the first, sick or disabled child, while others have found that these parents are more likely than the population at large to say they would have an abortion (Wertz et al. 1991). A study conducted in a rural area of the United States shows that most mothers would be against carrying out prenatal genetic diagnosis after the birth of a first, disabled child (Kelly 2009). However, it is important to know that in France more than $80 \%$ of women carrying a fetus with a diagnosis of cystic fibrosis (most of whom have already given birth to an affected child) choose to have an abortion (Agence de la biomédecine 2010). This shows the extent to which the French sociological context is more favorable to prenatal diagnosis than that of rural zones in the United States. These figures suggest it is preferable to indicate specifications for the genetic disease in question (perceived seriousness, recurrence rates, whether it is a physical or mental disorder, etc.) and the context in which the study is being conducted (country, time period, etc.) rather than using somewhat general terms such as "handicap," as is often the case in the literature. The second remark is linked to the fact that, as Shirley Hill (1994) rightly notes, people define health problems differently depending on social and cultural origins, as attested by the fact that mothers of African origin are less interested than others in prenatal diagnosis of sickle cell disease. It would therefore be useful 
to supplement my research with surveys of non-European populations, keeping in mind that European populations are overrepresented in the case of cystic fibrosis (Scotet et al. 2012).

In any case, a second pregnancy after the birth of a first child who has screened positive for cystic fibrosis represents an initial point of intersection between the quest for good health and the elimination of poor health. ${ }^{7}$ When it comes to family histories and caregivers' follow-up of second pregnancies, the prenatal approach is mixed in with the newborn screening-early treatment approach due to the family nature of genetic diseases. Mara Buchbinder and Stefan Timmermans (2011) also note this result in their study of newborn screening for metabolic diseases in the United States. More specifically, these authors look at both the dream of the "perfect child" and what links or differentiates newborn screening and prenatal diagnosis. From the point of view of the links between the two, they concentrate on the question of second pregnancies after the birth of a first affected child. However, this is far from the only intersection of the two approaches.

Another point of intersection is "heterozygous" individuals - that is, carriers of a genetic mutation; in the case of cystic fibrosis, this means they themselves do not have the disease (to have it, they would have to have two mutations). For technical reasons that need not be explained here, NSCF identifies approximately 2\% (400 to 500 children) of all heterozygous children born in France every year. People who, as newborns, screen heterozygous for cystic fibrosis and later wish to have children themselves will be able to request a genetic test. Likewise, relatives (uncles, aunts, cousins, etc.) of a child who has screened heterozygous are likely to be urged, probably by the child's parents, to consult a geneticist for prenatal diagnosis should they wish to have children. Two pediatricians said to parents of heterozygous children during appointments in connection with NSCF:

"You should inform your brothers and sisters [that they could be heterozygous], you shouldn't adopt the ostrich policy" (Pediatrician 1). 
"She [the baby screened at birth] is a carrier, she has one normal gene [...]. Perhaps the couple might consider doing a test when she wants a child" (Pediatrician 2).

The fact that some heterozygous individuals are identified through newborn screening thus induces the possibility of new prenatal diagnoses being carried out at some future time. The mothers I interviewed expressed a positive view of screening for heterozygotes. They said notably:

\footnotetext{
"That information is important; it's important to know that you've got it in the family [...]. It's important for collateral relatives who want to have children" (Mother 3).

"It's true that I find that afterwards you feel uneasy, but it's good to know it" (Mother 4).
}

Contrary to the previous case of a second pregnancy following the birth of a first child with the illness, here, for the most part, the families do not have any experience of a child suffering from cystic fibrosis. They do know enough about the illness, however, to consider that information regarding heterozygosity is interesting. For example, one mother of a child screened as a heterozygote said in an interview:

"You don't have a child so that he'll be unhappy though. Even if for some people cystic fibrosis isn't a big deal, for me it's huge. A child who can't run, who's immediately out of breath, it would have been really painful for me" (Mother 5).

In sum, NSCF seems to extend the possibilities of prenatal diagnosis. This initial intersection between the quest for good health and the elimination of poor health therefore leads to a shift between the two. Three characteristics can be highlighted: in practice, its most frequent result is prenatal diagnosis; the channel for this shift is a pre-identified genetic mutation, which establishes a technoscientific link between individuals; it is grounded in evaluating the lives of the children who screen positive. More specifically, what the brochures and statements express as an improvement in the quality of life of those affected is, as an indirect result, linked to practices of prenatal diagnosis that imply an evaluation of future life: it is not simply a case of providing the best possible care, it is also a case of considering the contingency of 
existence itself. This is also the case - and to a greater extent - when we consider the next point of intersection, to which we shall now turn.

\section{Playing for time and evaluating life}

The point of intersection at stake here, between the two approaches before and after birth, also entails a shift from the quest for good health to the elimination of poor health. However, I shall show that in comparison with the previous situation, it does not have the same practical results (it does not result in an individual prenatal diagnosis), it works through a different channel (it is not based on genetic mutations) and its foundations are expressed slightly differently (it rests on an even clearer expression of the evaluation of the lives of the sick or disabled).

Firstly, as the information sheet cited above suggests, it is important to underscore that having a quality of life thanks to NSCF consists above all in providing adequate treatment early ("early, rigorous treatment [...] ensure a higher quality of life"). However, this argument regarding timeframe has been taken further. During the study, a substantial proportion (nearly half) of mothers or parents of screened children - and an even greater proportion (two-thirds) of mothers or parents of a child who screened positive-had questioned clinicians about why the test was not carried out during pregnancy. They also expressed this question in the interviews during which timeframe emerged as a key topic once again. For example, just after her son screened positive, one mother explained from the very beginning of the interview:

"We lost a lot of time, [...], it's a shame not to do it [screening] before" (Mother 6).

When fathers were present during the interviews or observations, they sometimes expressed the same wish:

“I don't know why it wasn't done before [slight laughter]. [...] It's good that it's done, but shouldn't it be done before?" (Father 1). 
Lastly, one of the mothers whose child screened negative expressed the following question on this subject during the interview:

"It would be good, I think, if we tried to see if we couldn't detect some diseases earlier, when the amniocentesis is done" (Mother 5).

It is very much as if the concern for early detection that infuses the entire newborn screening process had been extended backward into the prenatal period. This situation is not specific to the center I studied, since geneticists from other areas in France raised the same question during meetings and interviews.

This issue can be considered from a historical perspective, because the reasoning that these mothers are reproducing is age-old among French doctors. As early as the seventeenth century, a discipline called "callipédie" (the art of bearing beautiful children) was devised to handle problems relating not only to birth and early child-raising but also to pregnancy (Carol 1995). In the late nineteenth century, medical disciplines such as pediatric nursing and venereology gradually led pediatricians to move progressively backward in time to consider pregnancy and ascendants in their attempts to explain and combat certain pathologies (Ibid. 1995). There is, therefore, a body of historical evidence suggesting a tendency to follow this path backward in time and this tendency is consistent with what we are seeing in the field today.

Secondly, once the idea of screening all fetuses is put forward, the question of the child's future life and of evaluating that life is raised. During an interview one mother said:

“It would be good to know if there's a disease, honestly, it's a very particular way of life, it's quite hard. [...]. To be honest, on top of it if they could do [...] just a blood test when a woman is pregnant. If it's explained properly to her afterwards, because it's really... Just now [...] he seems fine, but you know it's not always easy" (Mother 1).

A mother interviewed just after screening said: 


\begin{abstract}
"You really don't want to give birth today [...] to a child who's going to become an adult who'll already have a much heavier burden to carry than the others. You live from it [live with it], of course, but you take away the evolution to freedom from people [...]. It really is quite a blow. [...] I think if I'd known before, yes I wouldn't have kept my baby [...]. Having a sick child is quite something" (Mother 6).
\end{abstract}

One father, after have argued in the interview for generalized prenatal screening, continued:

"You're going to have to take care of him for a whole lifetime" (Father 1).

After having expressed regret regarding the lack of generalized prenatal screening, the mother of a child screened at birth concluded:

"The child himself is not happy" (Mother 5).

Obviously the issue conflicts with the attachment and love parents feel for the child that has already been born. At the same point during the interview, they also said:

"I'm not sorry I had my son. [...] Today he's here, I love him, he's my child" (Mother 4).

"If I had to do it over again [respondent points to her sick child], I'd still have this one" (Mother $1)$.

In one case, the father could not actually bring himself to utter what would probably have seemed to him a negation of his daughter's existence - a daughter whom he cares for very attentively—saying simply:

"If they had told us [before birth], 'Your child has cystic fibrosis'... I don’t know...” (Father 2).

In the end it was his wife who expressed their common wish for general prenatal screening. The value of the child is sometimes reasserted at the same moment, as in the case of a mother who could not hold back from adding about her sick son:

"He’s still a great little guy" (Mother 1).

Lastly, parents occasionally see a connection between the difficulties faced by sick children and their parents, on the one hand, and the socio-economic environment of the family and the country's social policies on the other. In doing so, they make it possible to distinguish the 
issue of insufficient social integration of sick or disabled people from that of the limitations of biomedical treatment:

"I'm from family where I get a lot of help. But if you take the case of people who are a lot more underprivileged [...], it's really a huge blow" (Mother 6).

"Someone who doesn't have very much money, who finds herself with a child like that, in terms of aid, you can't really say we get much help [...] overall” (Mother 5).

Thus, another shift from one approach to the other is due to the fact that NSCF has changed people's thinking on mass screening for pregnant women. In other words, the "regime of entrenchment" (Koch and Stermerding 1994) of NSCF facilitates the appearance of generalized prenatal screening.

Nonetheless, differences must be noted in comparison with the previous point. First, this further intersection does not result in individual prenatal diagnosis, but rather in a demand for mass screening. Second, it is channeled through the question of timeframe rather than the question of mutations (when a more or less serious mutation has already been identified within a family). Given that the major concern in NSCF is early detection, it is not surprising that a substantial proportion of mothers of screened children follow this approach to its logical conclusion, expressing surprise that the screening was of newborns - and therefore, according to them, already came too late. From the point of view of timeframe, it should nonetheless be underlined that it is possible that the mothers' viewpoints will change progressively as they move away from the moment of birth and as the child grows - a question that would require another research study. ${ }^{8}$ This seems consistent with criticisms against prenatal diagnosis made by the disabled rights movement in the United States (Parens and Asch 2000).

Finally, although, like in the previous case, this shift is grounded in an evaluation of the child's life, mothers (or parents) make this evaluation all the more because they are justifying the request of a practice that is currently unavailable. This should be linked to the fact that, 
unlike in other studies suggesting that the value of other people's lives, namely for those persons' relatives, is implicit or fragmentary (Fassin 2010; Gaille 2010), here this evaluation is most often expressed with great clarity. In return, this clear formulation then leads the parents to feel the need to also reaffirm their love for their child. Gail Landsman (2003) has explained that mothers of disabled children find themselves caught up in a paradox, simultaneously saying they love their children and that they would do anything to change them (i.e., remove the disability). Along the same lines, the mothers of screened children suffering from cystic fibrosis find themselves in a paradoxical situation, as they are simultaneously involved in combating the disease, loving the child that has it, and evaluating that child's life.

\section{Clinicians" "ethical practice" and "ethical work"}

The clinicians' points of view remain to be analyzed. These will allow another point of intersection to be highlighted that is not a shift but rather a tension between two elements. While the first of these two elements overlaps with some of the aspects analyzed above, the second is quite different and will lead me to outline the ethical questions that the clinicians may express as they develop their practices. Basing myself on Mitchell Dean's (1999) analysis of "ethical government" (in Michel Foucault's sense of the word) my analysis will focus on "ethical practice" (what is the aim of an action, in an ethical framework) and "ethical work" (how do the relevant actors work within an ethical framework).

The practice consisting in offering a prenatal diagnosis to a mother who has given birth to a first child diagnosed with cystic fibrosis does not give rise to much debate amongst clinicians, given how difficult caring for a sick child can be both for the family and the patient. One geneticist said in an interview: 
"We do a prenatal diagnosis because they have a first child with cystic fibrosis and two children with cystic fibrosis, even though we don't know how the illness will evolve in that child, it's a lot for one family" (Geneticist 2).

Traditionally, as numerous authors have underlined (in particular Lauritzen and Sachs 2001) the question is problematized in terms of the risk of giving birth to another sick child - a risk that is considered to be high because, for a recessive disease like cystic fibrosis, it is of $25 \%$. For example, one geneticist said in an interview:

"I tell people: you have a high risk of having a pathological pregnancy" (Biologist and Geneticist $1)$.

The practice consisting in identifying heterozygous children (who are not ill) at birth and informing their parents and, through them, their wider family is perceived in a more complex fashion by clinicians. For some of them, it is seen as positive as it could allow an increasing number of heterozygotes to be identified and, in the end, could avoid suffering. As one of the geneticists interviewed put it:

"You could say that treatments for this disease are actually relatively ineffective so this will be a means [...] of eradicating the disease. [...] I think it's a good thing for people to be aware of the possible risk of having a child who would be sick" (Biologist and Geneticist 1).

However, most clinicians, whether pediatricians or geneticists, perceive such identifications negatively, for several reasons. First, the aim and indeed the very sense of their own actions is at stake: detecting heterozygous individuals is not the same thing as identifying potentially sick persons for the purpose of treating them; instead it means detecting a genetic characteristic that may lead to a prenatal test. In other words, this practice is likely to shift their attention from the living, suffering child (the patient) toward descendants of the future adult and his or her existing family (heterozygous individuals):

"Diagnosing heterozygotes [...] is a necessary related consequence that cannot be neglected, but it's a problem. Let's just say it raises questions" (Pediatrician 2). 
Second, physicians may not feel comfortable about the developments that their own practices seem to be facilitating or pushing forward. As they see it, identifying heterozygous individuals at birth and informing parents amount to identifying a rising number of heterozygous individuals, and some fear that as the information gets passed from relative to relative this may lead to mass screening for heterozygotes or "eugenics":

"We're following a fairly incredible line of logic here, where newborn screening for cystic fibrosis actually amounts to undisclosed mass [prenatal] screening” (Geneticist 1).

When biomedical actors feel that the meaning of their work could change or that it could have large-scale consequences, they raise questions about heterozygotes that seek to break down this link between the quest for good health and the elimination of bad health. In doing so, although they express it differently, they associate the identification of heterozygotes with a form of "flexible eugenics" (Taussig, Rapp and Heath 2005); i.e., eugenics arising from tension between the sum of parents' individual choices and a tendency to normalize fetuses through genetics. In this regard, the history of eugenics in France, distinctive in two respects, sheds useful light on this phenomenon. First, to the extent that eugenics was defended in France, its advocates were physicians and not statisticians and biologists, as in other countries (Carol 1995). This explains in part why it never developed very fully in France. At the moral level, strong eugenics - i.e., eugenics that would eliminate sick persons - ran contrary to both the personal convictions and professional ethos of physicians. At the professional level, a state policy of eugenics would have gone against physicians' liberal practice, threatening their freedom of action, prestige and income (Ibid. 1995). As for private or family eugenics, it never found partisans in France. The relatively weak historical presence or attractiveness of eugenics in that country helps to understand at least in part today's French context, in which the elimination of poor health on a mass scale remains a sensitive subject of the sort that is 
instrumental in forging an ethos. These remarks allow a better understanding of the following point.

Regarding the link with generalized prenatal screening, this leads us back to the timeframe argument for early screening. In my interviews with clinicians, some explained that patients diagnosed at the age of six or seven might be experiencing much poorer health-due to lack of appropriate immediate attention - than if they had been diagnosed earlier. More generally, as anthropologist Patricia Kaufert put it (2000, 176): “The temptation, particularly for clinicians, is to continually push back the boundaries and 'find' the disease at an earlier stage." However, none of the pediatricians and geneticists I met with in the hospital openly advocated screening the fetuses of all pregnant women for cystic fibrosis. One geneticist did say during an interview that he wondered whether, given the sums of money spent on newborn screening, "it would not actually be a good idea to screen during pregnancy," immediately adding that that would "smack of eugenics, not eugenics, but it would be a little disturbing to prevent all those children from being born" (Geneticist 2). The same geneticist said in passing to parents during a consultation:

"We screen at birth. It would perhaps have been better to do it pre-natally, but that's how it is" (Geneticist 2).

Does this mean that newborn screening is changing professionals' views of prenatal screening? Yes, partially, but the possible association between prenatal screening and eugenics (or a similar idea) controls any impulse to generalize such screening. And this in turn makes it difficult to defend prenatal screening, or even utter the idea, because of moral values.

National statistics for France confirm that the above-cited principles are indeed practiced. Approximately 560 prenatal fetal tests in connection with cystic fibrosis were carried out in France in 2009 , leading to approximately 50 pregnancy terminations for medical reasons 
(Agence de la biomédicine 2010); 180 sick babies were born. In the region of Brittany, where NSCF was implemented as early as the 1980s, a study shows a significant drop of approximately $40 \%$ in the incidence of cystic fibrosis, linked to prenatal diagnoses (all techniques included) (Scotet et al. 2012). More broadly, it should be underlined that the decrease in incidence of cystic fibrosis linked with NSCF is not specific to France, as it has also been observed in regions of Great Britain and Australia (Ibid. 2012). To come back to the French case, clinicians consider prenatal diagnosis to be legitimate to such an extent that it affects the size of the sick population, but only on condition that a certain proportion of affected children are allowed to be born.

In short, for most clinicians the shift from the quest for good health and the elimination of poor health is considered as legitimate as long as it takes place at the individual level, not at the level of health policy. This is part of an individuation process that is familiar to sociologists and historians of biomedicine (Clarke et al. 2003; Turner 2000). The fact that this shift does not exist within the framework of a generalized health policy is linked to the fact that the ethical framework places an obstacle between two, thus replacing the channels previously observed. According to the majority position, the recognition of ethical obligations is encouraged notably by professional deontology (the role of the doctor is to treat patients) and/or law (French law restricts genetic tests). But that view is not unanimous amongst the professional caregivers. Some of them defend a different view by emphasizing their desire to reduce suffering by promoting the eradication of the disease before birth. The two sides to this tension show that the aim, or in other words the "ethical practice", is always to avoid suffering, but that beyond this shared goal, the means or "ethical work" through which to achieve this are varied and sometimes even opposed: taking the elimination of poor health even further, with a view to eradication, can be seen as either legitimate or illegitimate. 


\section{Conclusion}

The starting point for this text was the question of the sociological knot of birth, located at the intersection between the question for good health for persons suffering from genetic diseases and the elimination of poor health for fetuses. My study shows that there is not simply a contradiction between these two approaches but in fact a tension between this contradiction and a relationship where one can lead to the other. The first part of this tension comes from the ethical reservations of clinicians who are alarmed by the risk of eugenics, as analyzed above. The second rests on the fact that the threshold of birth is becoming less marked in particular due to the temporal link that can be drawn between the fetus of 8.5 months and the 1 month-old newborn. This continuity is accentuated by similarity between technologies used (when looking for mutations in children or fetuses). Finally, the study shows that this shift between the two approaches is grounded in a transition from the notion of "quality of life", which is foregrounded in newborn screening, to the notion of evaluating life. And this last point warrants close attention.

Generally speaking, it should be noted that the notion of "quality of life" informs and infuses increasing numbers of discourses today (Leplège 2004; Armstrong et al. 2007). It is linked to the historical movement outlined in introduction to integrate health, life and welfare into political strategies (Foucault 2001): understanding that it is possible to determine what policies are particularly effective in increasing general and collective welfare was what made it possible to devise and implement means of measuring "quality of life" (Leplège 2004). Moreover, the question of the value attributed to people's lives arises in connection with all biomedical techniques that require assessing "quality of life" in order to make informed decisions about what actions should be taken. This is clear from the scientific and social 
debates around choices to be made in matters of euthanasia, neonatal resuscitation, amniocentesis and prenatal diagnosis. Particularly because genetic diseases are hereditary, they elicit concern about the lives of family members who have or, in the case of descendants, might have the disease and about the health or welfare of future children (Petersen 2006; Ehrich et al. 2006). ${ }^{9}$ This explains the view of some sociologists and anthropologists that behind prenatal diagnosis lurks the question of what kind of life is worth living (Landsman 2003; Press and Browner 1997). It should be clear that what is at stake in all these questions not only encompasses but exceeds the "quality of life" issue. Because of the connection with prenatal diagnosis, what is at stake actually includes both the living being and life itself. This is why I propose to exchange the concept of "quality of life" (qualite de vie) for the notion of "a quality life" (vie de qualité), as it is that notion that seems to be at the heart of people's practices. In view of the results presented, it seems to me that the notion of quality life offers a way of understanding some of the practices of biomedicalization that are currently undergoing change (Clarke et al. 2010).

For these different reasons, and despite the fact that prenatal and newborn approaches are enacted by different types of specialists using different intervention modes and that they have different social effects, it is not really tenable to separate them entirely in our increasingly medicalized societies. A constitutive element of the articulation is therefore linked to the aim of ensuring good health in wealthy nations, whether this is carried out before or after birth. Families are under the surveillance of both obstetricians and pediatricians, and my study shows that we are not dealing with mere parallel advances in two different techniques but a causal link between the two. There are situations where an increasingly demanding fetal selection approach and increasingly attentive patient care converge. Against the widespread understanding that social inclusion of disabled persons is antagonistic to the exclusion of 
"sick" fetuses, the quest for good health and the elimination of poor health do not seem to neutralize each other but rather to bolster each other: the more attentive we are to including sick or disabled persons, the more likely we are to exclude fetuses. Some add concerns about or accusations of "eugenics". I would not use that term in this context because, following Nikolas Rose (2007), I see today's policies and practices as complex and new enough to deserve their own vocabulary. What my field study suggests is that the tension seems to be shifting in favor of a move backward in time - toward the fetus, in connection with the idea of early diagnosis that permeates all of current biomedicine (Grimes and Schulz 2002). The future will tell whether or not this observation is well-founded.

\section{References}

\section{Bibliography}

Agamben, Giorgio. 1998 [1995]. Homo Sacer: Sovereign power and bare life. Stanford: Stanford University Press.

Armstrong, David. 2012. Screening: Mapping medicine's temporal spaces. Sociology of Health \& Illness 34(2):177-193.

Armstrong, David, Lilford, Richard, Ogden, Jane, and Simon Wessely. 2007. Health-related quality of life and the transformation of symptoms. Sociology of Health \& Illness 29(4):570-583.

Buchbinder, Mara, and Stefan Timmermans. 2011. Medical technologies and the dream of the perfect newborn. Medical Anthropology 30(1):56-80.

Carol, Anne. 1995. Histoire de l'eugénisme en France. Les médecins et la procréation XIX $X X^{e}$ siècle. Paris: Seuil. 
Cayla, Olivier, and Yan Thomas. 2002. Du droit de ne pas naître. A propos de l'affaire Perruche. Paris: Gallimard.

Clarke, Adele E., Mamo, Laura, Fosket, Jennifer Ruth, Fishman, Jennifer R., and Janet K., Shim (eds.) 2010. Biomedicalization: technoscience, health, and illness in the U.S. Durham: Duke University Press.

Dean, Mitchell. 1999. Governmentality: Power and rule in modern society. London, Thousand Oaks, New Delhi: SAGE.

Ehrich, Kathryn, Williams, Clare, Scott, Rosamund, Sandall, Jane, and Bobbie Farsides. 2006. Social welfare, genetic welfare? Boundary-work in the IVF/PDG clinic. Social Science \& Medicine 63(5):1213-1224.

Fassin, Didier. 2010. Evaluer les vies. Cahiers internationaux de sociologie CXXVIIICXXIX:105-116.

Foucault, Michel. 2001[1994]. Dits et écrits [1976-1988]. Paris: Gallimard.

Fox, Renée C. 2000. Medical uncertainty revisited. In The handbook of social studies in health and medicine, ed. G.L. Albrecht, R. Fitzpatrick, and S.C. Scrimshaw, 259-276. London, Thousand Oaks, New Delhi: SAGE.

Gaille, Marie. 2010. La valeur de la vie. Paris: Les Belles Lettres.

Glaser, Barney G., and Anselm Strauss. 1967. The discovery of grounded theory. London: Aldine.

Grob, Rachel. 2011. Testing babies. The transformation of newborn screening, parenting, and policymaking. New Brunswick, London: Rutcher University Press.

Grimes, David A., and Kenneth F. Schulz. 2002. Uses and abuses of screening tests. Lancet 359(9309):881-884. 
Guthrie, Robert and Ada Susi. 1963. A simple phenylalanine method for detecting phenylketonuria in large populations of newborn infants. Pediatrics 32(3):338-343.

Hacking, Ian. 2005. Seminar 'Façonner les gens', Collège de France, Paris.

Hill, Shirley A. 1994. Motherhood and the obfuscation of medical knowledge: The case of sickle cell disease. Gender and Society 8:29-47

Kaufert, Patricia A. 2000. Screening the body: The pap smear and the mammogram. In Living and working with the new medical technologies. Intersections of inquiry, ed. M. Lock, A. Young, and A. Cambrosio, 165-183. Cambridge: Cambridge University Press.

Kelly, Susan E. 2009. Choosing not to choose: Reproductive responses of parents of children with genetic conditions or impairments. Sociology of Health \& Illness 31(1):81-97.

Koch, Lene, and Dirk Stemerding. 1994. The sociology of entrenchment: A cystic fibrosis test for everyone? Social Science \& Medicine 39(9):1211-1220.

Landsman, Gail. 2003. Emplotting children's lives: Developmental delay vs. Disability. Social Science \& Medicine 56(9):1947-1960.

Lauritzen, Sonja O., and Lisbeth Sachs. 2001. Normality, risk and the future: Implicit communication of threat in health surveillance. Sociology of Health \& Illness 23(4):497516.

Leplège, Alain. 2004. Qualité de vie (Mesures de la). In Dictionnaire de la pensée médicale, ed. D. Lecourt, 939-940. Paris: Presses Universitaires de France.

Parens Erik, and Adrienne Asch. 2000. Prenatal testing and disability rights. Washington: Georgetown University Press.

Petersen, Alan. 2006. The best experts: The narratives of those who have a genetic condition. Social Science \& Medicine 63(1):32-42. 
Press, Nancy, and C.H. Browner. 1997. Why women say yes to prenatal diagnosis. Social Science \& Medicine 45(7):979-989.

Rapp, Rayna, and Faye D. Ginsburg. 2001. Enabling disability: Rewriting kinship, reimaging citizenship. Public Culture 13(3):533-556.

Rapp, Rayna, and Faye D. Ginsburg. 2003. Standing at the crossroads of genetic testing: New eugenics, disability consciousness, and women's work. Available at: http://www.genewatch.org/genewatch/articles/15-1 crossroads.html.

Rose, Nikolas. 2007. The politics of life itself. Biomedicine, power and subjectivity in the twenty-first century. Princeton: Princeton University Press.

Scotet, Virginie, Duguépéroux, Ingrid, Saliou, Philippe, Rault, Gilles, Roussey, Michel, Audrézet, Marie-Pierre, and Claude Férec. 2012. Evidence for decline in the incidence of cystic fibrosis: A 35-year observational study in Brittany, France. Orphanet Journal of Rare Diseases 7:14.

Taussig, Karen-Sue, Rapp, Rayna, and Deborah Heath. 2005. Flexible eugenics: Technologies of the self in the age of genetics. In Anthropologies of modernity, ed. J.X. Inda, 194-212. Malden, Oxford, Victoria: Blackwell Publishing.

Timmermans, Stefan, and Mara Buchbinder. 2013. Saving babies? The consequences of newborn genetic screening. Chicago: Chicago University Press.

Turner, Brian S. 2000. Changing concepts of health and illness. In The handbook of social studies in health and medicine, ed. G.L. Albrecht, R. Fitzpatrick, and S.C. Scrimshaw, 923. London, Thousand Oaks, New Delhi: SAGE.

Vailly, Joëlle. 2008. The expansion of abnormality and the biomedical norm: neonatal screening, prenatal diagnosis and cystic fibrosis in France. Social Science \& Medicine 66(12):2532-2543. 
Vailly, Joëlle. 2013. The birth of a genetics policy. Social issues of newborn screening. Farnham: Ashgate.

Ville, Isabelle. 2011. Disability policies and perinatal medicine: The difficult conciliation of two fields of intervention on disability. ALTER European Journal of Disability Research $5: 16-25$.

Wertz, Dorothy C., Rosenfield, Janet M., Janes, Sally R., and Richard W. Erbe. 1991. Attitudes toward abortion among parents of children with cystic fibrosis. American Journal of Public Health 81(8):992-996.

\section{Documents}

AFDPHE. 2001. 3 jours, l'âge du dépistage, AFDPHE (Assurance maladie - Sécurité sociale, Ministère de l'emploi et de la solidarité), Paris.

Agence de la biomédecine. 2010. Rapport annuel. Bilan des activités, Saint-Denis.

Assurance Maladie - Sécurité Sociale. 2000. Dossier de Presse "Un dépistage systématique de la mucoviscidose", Paris.

1. This study was funded by the GIS-Institut des Maladies Rares. The initial text was translated by Amy Jacob and a later version was revised by Lucy Garnier. I would like to thank the anonymous reviewers for their comments on a previous version of the article.

${ }^{2}$. By definition, screening means identifying individuals within a given population who are at risk for a disease (in which case screening is followed by a diagnostic confirmation test) or who already have it without being aware of it.

${ }^{3}$. See the website of the National Newborn Screening Status Report: http://genes-rus.uthscsa.edu/sites/genes-r-us/files/nbsdisorders.pdf 
${ }^{4}$. Cystic fibrosis is usually characterized by severe respiratory and digestive disorders, though the severity of these disorders varies greatly. Life expectancy in France for a person with cystic fibrosis is approximately 37 years.

5. Ian Hacking (2005) takes up the term used by psychiatrist Ronald David Laing, according to which psychosis can sometimes be considered as the result of intertwined and contradictory desires.

${ }^{6}$. More often than not, several observations of consultations were conducted with the same family, which explains the difference between the number of interviews and the number of observations.

7. The so-called "mild" forms of cystic fibrosis diagnosed through screening at birth, which usually result in minor symptoms (pancreatisis, male infertility, etc.) or even no symptoms at all, are a notable variant to this situation. As I have shown in another article, they offer a point of intersection between the newborn and the prenatal grounded in an extension of the idea of abnormality to screened newborns, and to later pregnancies (Vailly 2008).

${ }^{8}$. In support of this idea we have Landsman's (2003) result that once mothers have understood that their child will probably never correspond to the notion of a "normal" child, most reassess the meaning and value of normality, becoming critical of a discourse that would diminish the value of their child.

9. A significant example of the growing influence of biomedicine in this matter is suggested by in vitro fertilization and pre-implantation genetic diagnosis in Great Britain. Those practices were subject to a law requiring that the welfare of children so produced be assessed beforehand by a medical unit using medical and social criteria (Ehrich et al. 2006). 